\title{
PENGARUH DESAIN BUKAAN TERHADAP PENCAHAYAAN ALAMI STUDI KASUS SMA NEGERI 1 DOLOK BATU NANGGAR
}

\author{
Safirannur ${ }^{1}$, Adi Safyan Yahya ${ }^{2}$, Yenny Novianti ${ }^{3 *}$ \\ ${ }^{1}$ Prodi Arsitektur Universitas Malikussaleh, email: safirannur.160160011@mhs.unimal.ac.id \\ ${ }^{2}$ Prodi Arsitektur Universitas Malikussaleh, email: adi.safyan@unimal.ac.id \\ 3*Prodi Arsitektur Universitas Malikussaleh, email: yenny.novianti@unimal.ac.id
}

\begin{abstract}
ABSTRAK
Pencahayaan alami adalah sumber energi yang sangat dibutuhkan dalam memenuhi penerangan pada bangunan, khususnya di sekolah. Sekolah sebagai sarana pada kegiatan belajar dan mengajar sangat membutuhkan pencahayaan alami, Penelitian ini dilakukan untuk mengidentifikasi pengaruh desain bukaan terhadap pencahayaan alami dan intensitasnya terhadap ruang berdasarkan SNI-2001. Ruang belajar di SMA Negeri 1 Dolok Batu Nanggar, Sumatera Utara memiliki beberapa bukaan dengan ukuran dan orientasi berbeda. Perbedaan tersebut sangat signifikan baik dari segi ukuran, bentuk, posisi dan orientasi di setiap ruang. Hal inilah yang menjadi latar belakang untuk meneliti terkait pengaruh bukaan terhadap pencahayaan alami pada ruang belajar. Penelitian ini dilakukan dengan pendekatan kuantitatif. Metode penelitian dalam pengukuran intensitas cahaya dan luas bukaan dilakukan saat kondisi langit cerah dan mendung mulai pukul 08.00 WIB hingga 15.00 WIB. Populasi pada penelitian ini, berjumlah 32 ruang belajar di SMA Negeri 1 Dolok Batu Naggar. Sampel penelitian berjumlah 9 ruang belajar. Pengaruh bukaan terlihat dari intensitas pencahayaan alami dan WWR. WWR memenuhi standarisasi pencahayaan ruang belajar sebesar $20 \%$ di kondisi langit cerah; WWR 14\%-18\% memenuhi standar pencahayaan pada pukul 11.00-15.00 WIB dan WWR dibawah 14\% tidak memenuhi standar pencahayaan mulai pukul 08.00-15.00 WIB. Intensitas pencahayaan alami di kondisi langit mendung tidak memenuhi standar pada seluruh sampel. Penelitian ini menemukan pengaruh bukaan terhadap intensitas pencahayaan alami sangat berperan dan didukung oleh wwr. sehingga standar pencahayaan alami yang terpenuhi hanya berada pada sampel 1, 3 dan 9.
\end{abstract}

Kata kunci: desain bukaan, pencahayaan alami, sekolah, ruang kelas, faktor langit

Info Artikel:

Dikirim: 25 Agustus 2021; Revisi: 27 September 2021; Diterima: 29 September 2021; Diterbitkan: 30 September 2021

(C)2021 The Author(s). Published by Arsitekno, Architecture Program, Universitas Malikussaleh, Aceh, Indonesia under the Creative Commons Attribution 4.0 International License (https://creativecommons.org/licenses/by/4.0/).

\section{PENDAHULUAN}

Pencahayaan alami menjadi komponen penting dalam perancangan sebuah bangunan. Pencahayaan alami menjadi salah satu syarat yang perlu terpenuhi dalam sistem pencahayaan bangunan [1]. Cahaya matahari menjadi sumber pencahayaan alami yang dapat digunakan untuk pencahayaan suatu bangunan. Sumber energi matahari dapat difungsikan untuk mengurangi penggunaan listrik pada bangunan.

Pencahayaan pada suatu ruang tidak hanya terfokus pada objek benda yang ada di dalamnya, tetapi juga mencakup perasaan nyaman sehingga mampu membentuk kondisi ruang yang menyenangkan [2]. Pencahayaan yang buruk, juga berpengaruh pada kesehatan pengguna ruang. Dampak lainnya, antara lain: stres, ketidaknyamanan visual (mata), migrain, nyeri dan gejala lainnya yang disebut dengan building syndrome [3]. Pencahayaan alami yang kurang optimal pada suatu bangunan dapat diakibatkan oleh berbagai permasalahan [4]. Kondisi 
tersebut dijelaskan dalam SNI Tahun 2001 mengenai perancangan sistem pencahayaan alami pada bangunan gedung yakni mengenai proses masuknya cahaya matahari menuju bangunan yang dapat terhalangi oleh bangunan itu sendiri maupun bangunan lain disekitarnya [5].

Pencahayaan alami menjadi hal yang mendasar pada perancangan suatu bangunan, tanpa terkecuali dalam bangunan sekolah [6]. Ruang belajar (kelas) merupakan bagian terpenting dari aktifitas belajar mengajar, sehingga selayaknya memenuhi standart kebutuhan sistem pencahayaan yang tepat agar kondisi lebih optimal dan nyaman. Syarat dan ketentuan sebuah ruang kelas sebagai prasarana sekolah telah ditetapkan dalam Peraturan Menteri Pendidikan Republik Indonesia Nomor 24 Tahun 2007 mengenai sarana dan prasarana sekolah. Syarat dan ketentuan yang harus dipenuhi, yaitu: sirkulasi, luasan ruang minimum serta pencahayaan. Berdasarkan SNI 2001 mengenai konservasi energi pada sistem pencahayaan, kebutuhan pencahayaan minimum yang harus dipenuhi oleh sebuah ruang kelas yaitu sebesar 250 lux [7]. Mutu pencahayaan alami yang tepat tidak terlepas dari distribusi pencahayaan yang dipengaruhi oleh orientasi, bentuk dan warna bangunan [8]. Faktor lainnya yang mempengaruhi pencahayaan alami pada ruang antara lain tipe, ukuran, bentuk, posisi dan orientasi bukaan yang terdapat pada sebuah ruang [9].

Ruang belajar memiliki orientasi, bentuk dan luas bukaan yang berbeda. Hal tersebut mengakibatkan distribusi cahaya matahari yang tidak merata. Distribusi tersebut berpengaruh pada proses pembelajaran dengan media papan tulis. Media papan tulis hitam dan putih pada ruang belajar akan dipengaruhi oleh kuatnya cahaya yang masuk menuju ruang. Distribusi cahaya yang tidak merata di dalam ruang kelas dapat menimbulkan efek silau atau gelap ketika melihat ke arah papan tulis pada posisi tertentu [10].

Kebutuhan terhadap pencahayaan alami yang memenuhi standar pada ruang belajar perlu diteliti agar dapat diidentifikasi ruang yang memenuhi standar minimum pencahayaan berdasarkan fungsi ruangnya. Hal inilah yang menjadi latar belakang dan mendorong peneliti untuk mengevaluasi desain bukaan yang optimal berdasarkan standar kebutuhan pencahayaan alami sebagai acuan dalam mendesain bukaan.

\section{METODE PENELITIAN}

Penelitian dilakukan dengan pendekatan kuantitatif, agar mampu mengidentifikasi pengaruh desain bukaan terhadap pencahayaan alami dan intensitasnya secara terukur. Teknik analisa data dengan perhitungan matematis terkait pengukuran terhadap perhitungan kuat penerangan (E). Pendekatan kuantitatif ini, tentunya berkaitan erat dalam pengukuran, perhitungan dan pengamatan terhadap pencahayaan alami. Adapun variabel yang diteliti, mencakup variabel bebas dan terikat. Variabel bebas yaitu desain bukaan sedangkan variabel terikat yakni pencahayaan alami (tabel 1).

Tabel 1. Variabel Penelitian

\begin{tabular}{|c|c|c|c|}
\hline $\begin{array}{l}\text { Variabel } \\
\text { Bebas }\end{array}$ & $\begin{array}{l}\text { Variabel } \\
\text { Terikat }\end{array}$ & Keterangan & Teori \\
\hline \multirow{4}{*}{$\begin{array}{l}\text { Pencahayaan } \\
\text { Alami }\end{array}$} & $\begin{array}{l}\text { Orientasi } \\
\text { Bangunan }\end{array}$ & $\begin{array}{l}\text { Orientasi bangunan akan memberikan banyak pengaruh terhadap banyaknya } \\
\text { sinar matahari yang masuk menuju ruang. }\end{array}$ & \multirow{4}{*}{$\begin{array}{l}\text { Lechner } \\
(1991)\end{array}$} \\
\hline & $\begin{array}{c}\text { Bentuk } \\
\text { Bangunan }\end{array}$ & $\begin{array}{l}\text { Bentuk bangunan akan membentuk zona-zona ruang yang menerima sebaran } \\
\text { cahaya. Sebaran cahaya pada bentuk denah tertentu menghasilkan zona } \\
\text { pencahayaan alami penuh, sebagian dan tanpa pencahayaan alami. }\end{array}$ & \\
\hline & $\begin{array}{l}\text { Perencanaan } \\
\text { Ruang }\end{array}$ & $\begin{array}{l}\text { Perencanaan ruang menjadi strategi yang ditujukan untuk menyesuaikan } \\
\text { kebutuhan pengguna seperti privasi visual dan akustik. }\end{array}$ & \\
\hline & $\begin{array}{c}\text { Warna } \\
\text { Bangunan }\end{array}$ & $\begin{array}{l}\text { Warna akan mempengaruhi banyaknya cahaya yang akan dipantulkan } \\
\text { pada ruang. Warna-warna ringan yang diaplikasikan pada ruang luar } \\
\text { maupun ruang dalam akan memantulkan lebih banyak cahaya }\end{array}$ & \\
\hline
\end{tabular}


Tabel 1. Lanjutan

\begin{tabular}{|c|c|c|c|}
\hline $\begin{array}{l}\text { Variabel } \\
\text { Bebas }\end{array}$ & $\begin{array}{l}\text { Variabel } \\
\text { Terikat }\end{array}$ & Keterangan & Teori \\
\hline \multirow{7}{*}{$\begin{array}{l}\text { Desain } \\
\text { Bukaan }\end{array}$} & Tipe Jendela & $\begin{array}{l}\text { Jendela memiliki beberapa tipe berdasarkan kegunaannya pada } \\
\text { bangunan. Kriteria dan sifat utama jendela antara lain untuk } \\
\text { pencahayaan alami, penghawaan alami dan visualisasi. }\end{array}$ & \multirow{7}{*}{$\begin{array}{l}\text { Manurung } \\
\quad(2012)\end{array}$} \\
\hline & $\begin{array}{l}\text { Ukuran } \\
\text { Jendela }\end{array}$ & $\begin{array}{l}\text { Ukuran jendela akan mempengaruhi penghawaan dan } \\
\text { visualisasi menuju luar bangunan. Ukuran jendela terdiri atas } \\
\text { permukaan jendela dan rasio bukaan ruang. }\end{array}$ & \\
\hline & $\begin{array}{l}\text { Bentuk } \\
\text { Jendela }\end{array}$ & $\begin{array}{l}\text { Bentuk dari jendela akan mempengaruhi cahaya yang } \\
\text { didistribusikan pada ruang. Distribusi cahaya akan } \\
\text { mempengaruhi kualitas ruang yang akan diterangi, kualitas } \\
\text { visualisasi dan sirkulasi. }\end{array}$ & \\
\hline & Posisi Jendela & $\begin{array}{l}\text { Jendela pada sebuah ruang biasanya berada pada posisi vertikal } \\
\text { dan horizontal. Posisi jendela pada ruang antara lain tinggi, } \\
\text { menengah dan rendah. }\end{array}$ & \\
\hline & $\begin{array}{l}\text { Orientasi } \\
\text { Jendela }\end{array}$ & $\begin{array}{l}\text { Pencahayaan alami ruang akan dipengaruhi oleh orientasi } \\
\text { jendela terhadap orientasi geografis dan garis edar matahari. }\end{array}$ & \\
\hline & $\begin{array}{l}\text { Sistem } \\
\text { Kontrol }\end{array}$ & $\begin{array}{l}\text { Sistem kontrol jendela difungsikan untuk mengatur jendela } \\
\text { sebagai akses masuknya cahaya. Sistem kontrol ini dapat } \\
\text { dilakukan secara manual ataupun otomatis. }\end{array}$ & \\
\hline & Tipe Jendela & $\begin{array}{l}\text { Jendela memiliki beberapa tipe berdasarkan kegunaannya pada } \\
\text { bangunan. Kriteria dan sifat utama jendela antara lain untuk } \\
\text { pencahayaan alami, penghawaan alami dan visualisasi. }\end{array}$ & \\
\hline
\end{tabular}

Populasi yang diteliti meliputi semua ruang belajar (kelas) di SMA Negeri 1 Dolok Batu Nanggar, dengan jumlah total adalah 32 ruang. Penentuan sampel dilakukan dengan teknik purposive sampling dengan kriteria inklusi. Kriteria inklusi merupakan kriteria yang dikembangkan berdasarkan kriteria sampel yang harus memenuhi teoritis dan sesuai dengan permasalahan pada topik penelitian. Adapun kriteria inklusi pada penelitian ini antara lain: pertama, ruang kelas dengan desain pencahayaan alami yang berbeda, desain tersebut mencakup orientasi, bentuk dan warna bangunan. Kedua, ruang kelas dengan desain bukaan yang berbeda, desain yang dimaksud mencakup tipe, ukuran, bentuk, posisi, dan orientasi. Berdasarkan teknik purposive sampling maka diperoleh total sampel berjumlah 9 ruang belajar. Adapun sampel pada penelitian ini, terdiri atas 9 sampel ruang kelas antara lain: X MIBB, $\mathrm{X}$ MIA-4, X MIS-4, XI MIS-1, XI MIS-2, XI MIA-1, XII MIA-5, XII MIA-2 dan XII MIBB (gambar 1).

Subjek maupun objek berada di jalan Sisingamangaraja, Kabupaten Simalungun, Provinsi Sumatera Utara. Subjek penelitian adalah SMA Negeri 1 Dolok Batu Nanggar (gambar 1). Objek penelitian yaitu ruang belajar (kelas) dengan total sampel berjumlah 9 unit (Tabel 2). Waktu penelitian dilakukan selama dua hari, yaitu di hari rabu, tanggal 10 februari 2021 dengan kondisi langit cerah tanpa awan. Interval waktu penelitian yaitu pukul 08.00-10.00 WIB, 11.0013.00 WIB dan 14.00-15.00 WIB, waktu berikutnya dalam pengukuran kedua dilakukan pada hari sabtu, tanggal 13 februari 2021 dengan kondisi langit mendung tertutup awan. Pengukuran dilakukan dalam interval sama. 


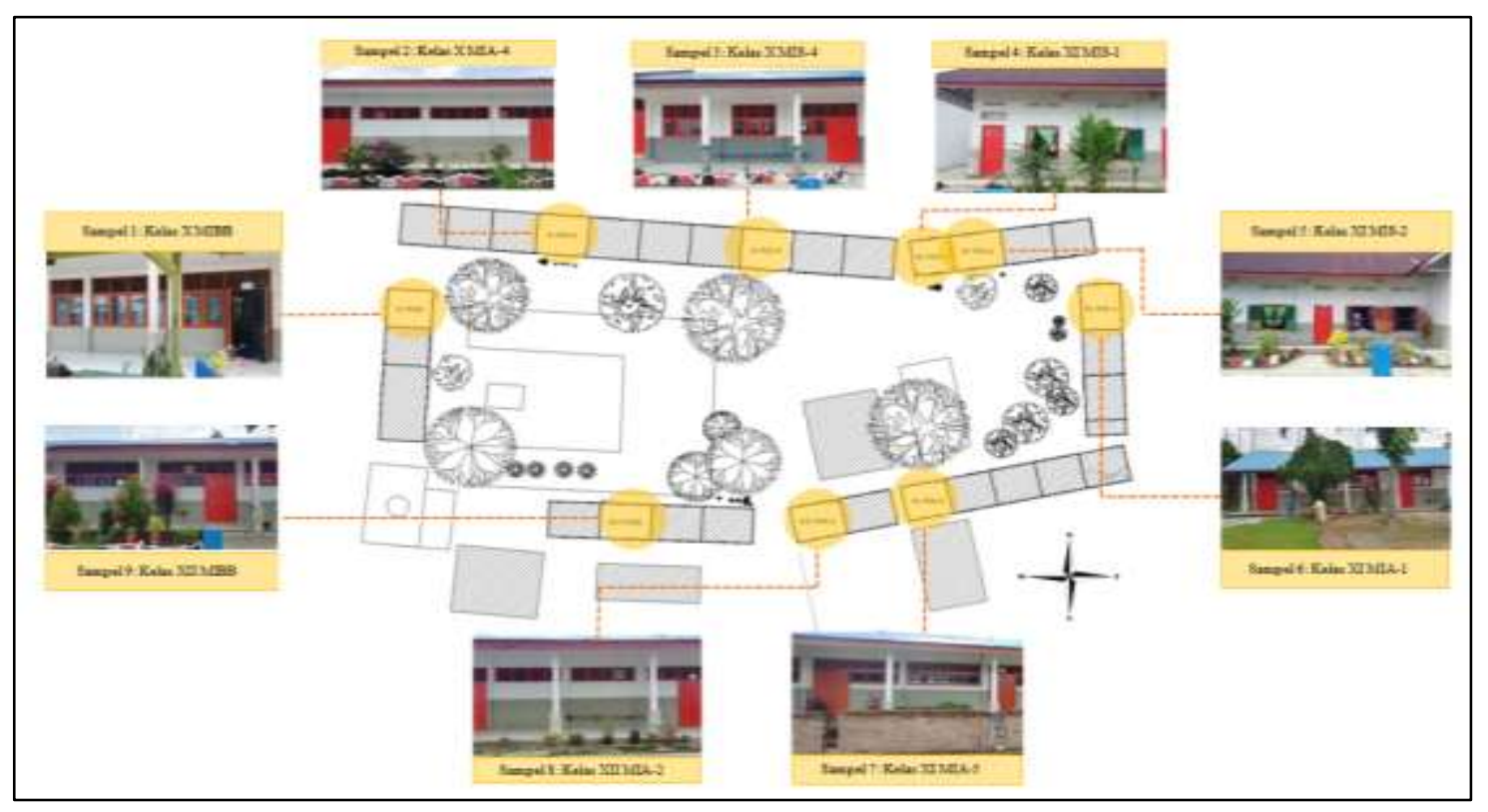

Gambar 1. Populasi dan Sampel Penelitian

Tabel 2. Denah Sampel Penelitian

\begin{tabular}{lll}
\hline Sampel Ruang Kelas Denah \\
\hline
\end{tabular}

1 X MIBB

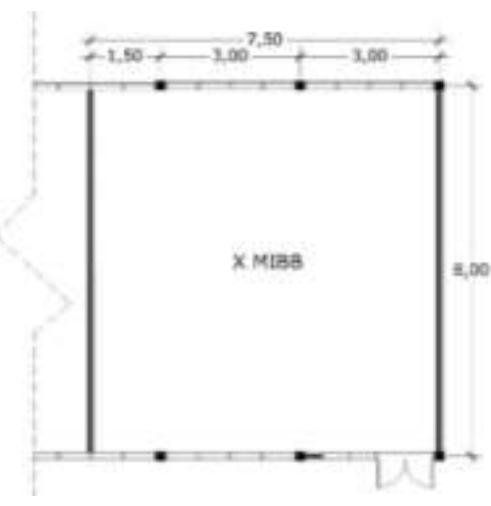

2 X MIA-4

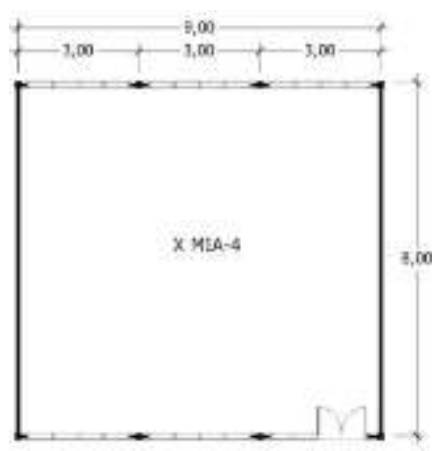




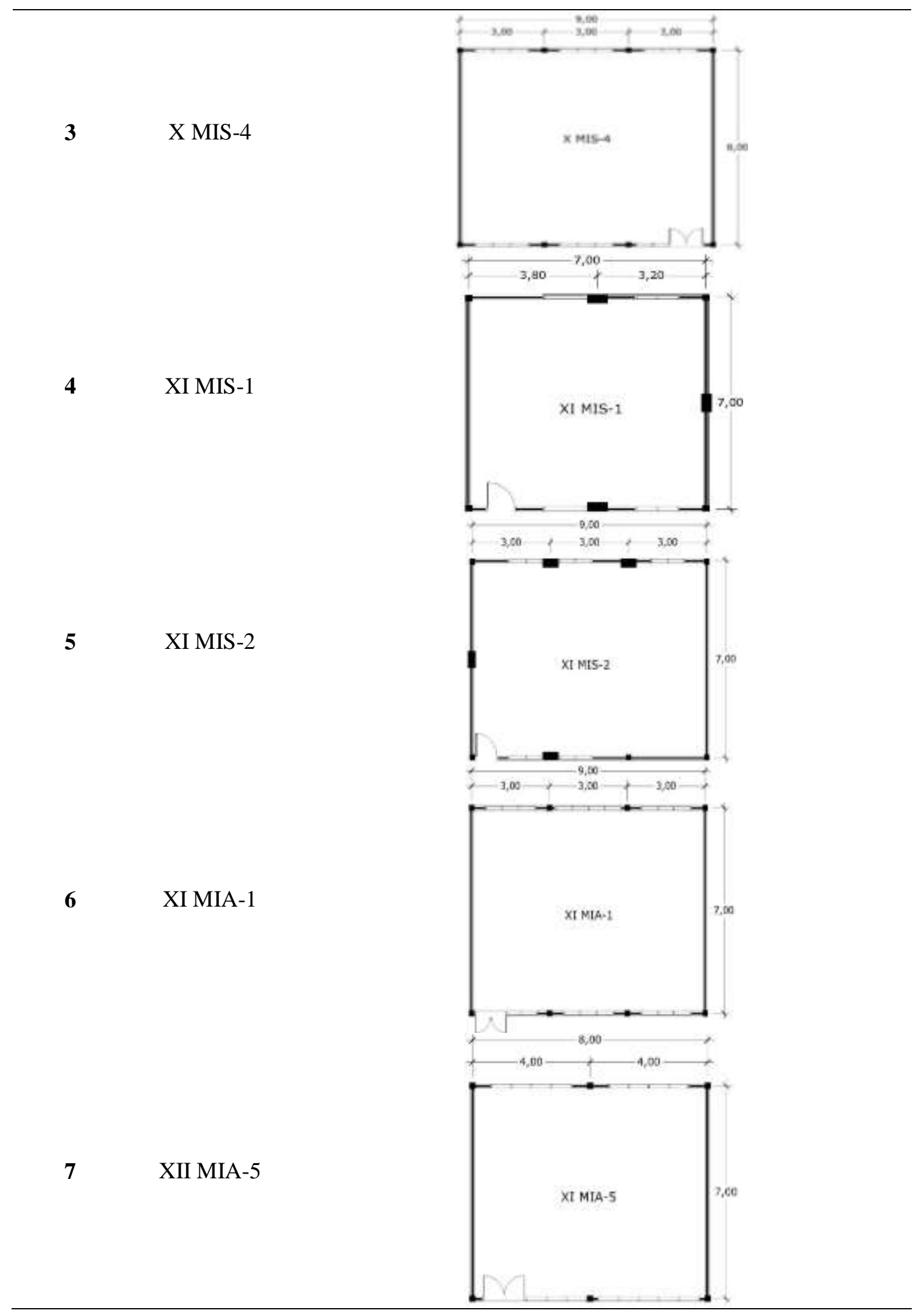




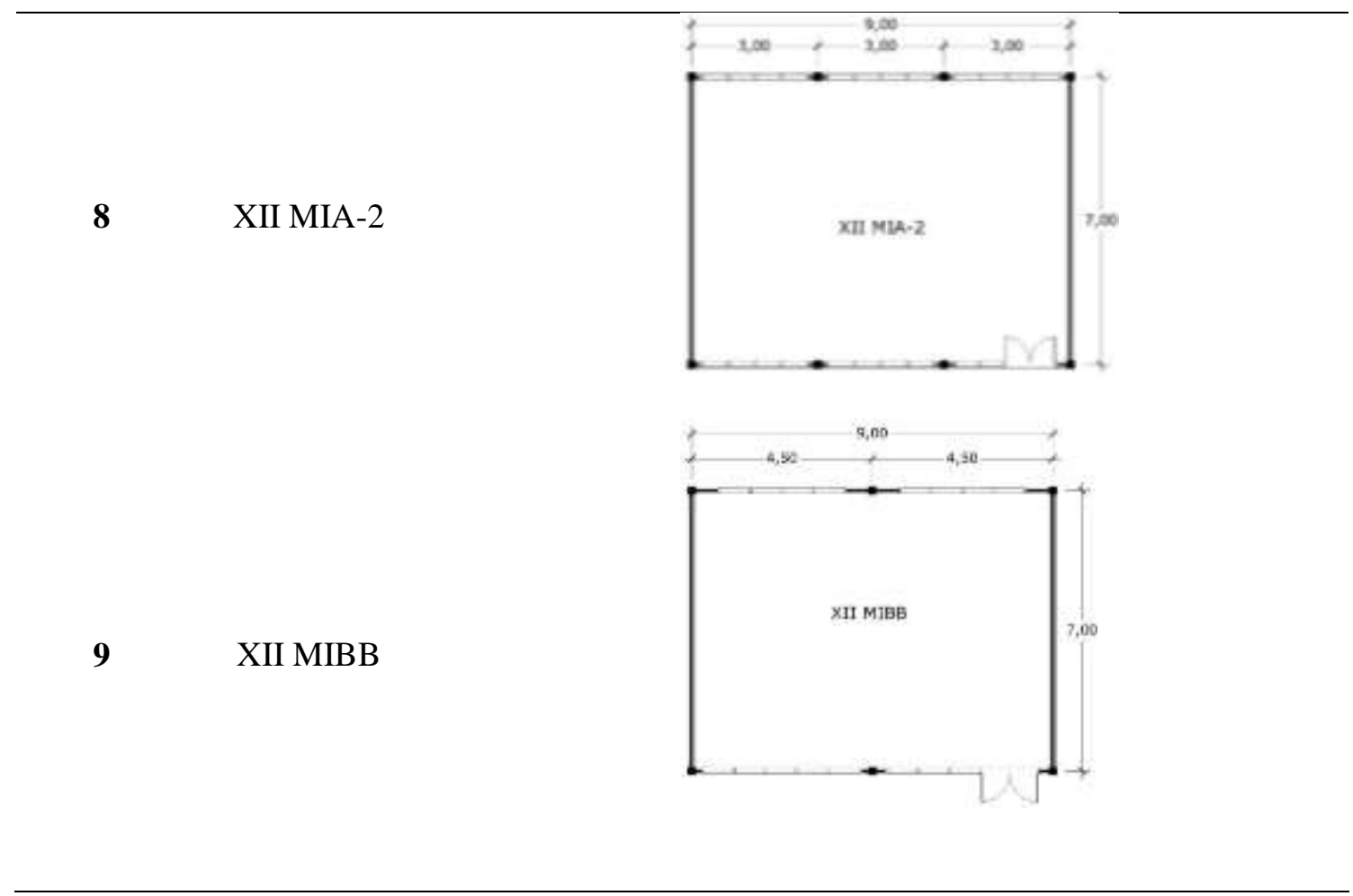

\section{HASIL DAN PEMBAHASAN}

Ruang belajar merupakan salah satu yang mampu mendukung dalam peningkatan kapasitas ilmu pengetahuan bagi seluruh siswa. Proses pembelajaran dimulai dari pukul 08.00 sampai dengan pukul 15.00, pada saat tersebut sangat dibutuhkan suasana belajar yang nyaman secara visual terkait dengan pencahayaan alami sebagai penerangan aktif yang dibutuhkan. Kondisi pencahayaan alami yang diperoleh tentunya juga dipengaruhi oleh tipe bukaan dan luas dari bukaan tersebut. Sistem pencahayaan alami, akan semakin baik jika luas bukaan semakin besar, akan tetapi tidak berdampak baik pada sistem penghawaan dalam ruangan karena pengaruh radiasi matahari yang banyak. Hal lainnya yang tidak berdampak baik karena mampu memicu kesilauan pada ruang. Aspek lainnya, dapat mempengaruhi pencahayaan alami yaitu orientasi bukaan dan keberadaan pembayang atau penghalang sinar matahari.

Faktor yang berpengaruh terhadap jumlah cahaya yang masuk menuju ruang antara lain tipe, ukuran, bentuk, posisi, orientasi dan sistem kontrol bukaan sebagai contoh di bukaan pintu maupun jendela [11]. Berikut ini, merupakan deskripsi detail bukaan jendela maupun pintu di ruang kelas SMA Negeri 1 Dolok Batu Nanggar (tabel 3). 
Tabel 3. Detail Bukaan Sampel Penelitian

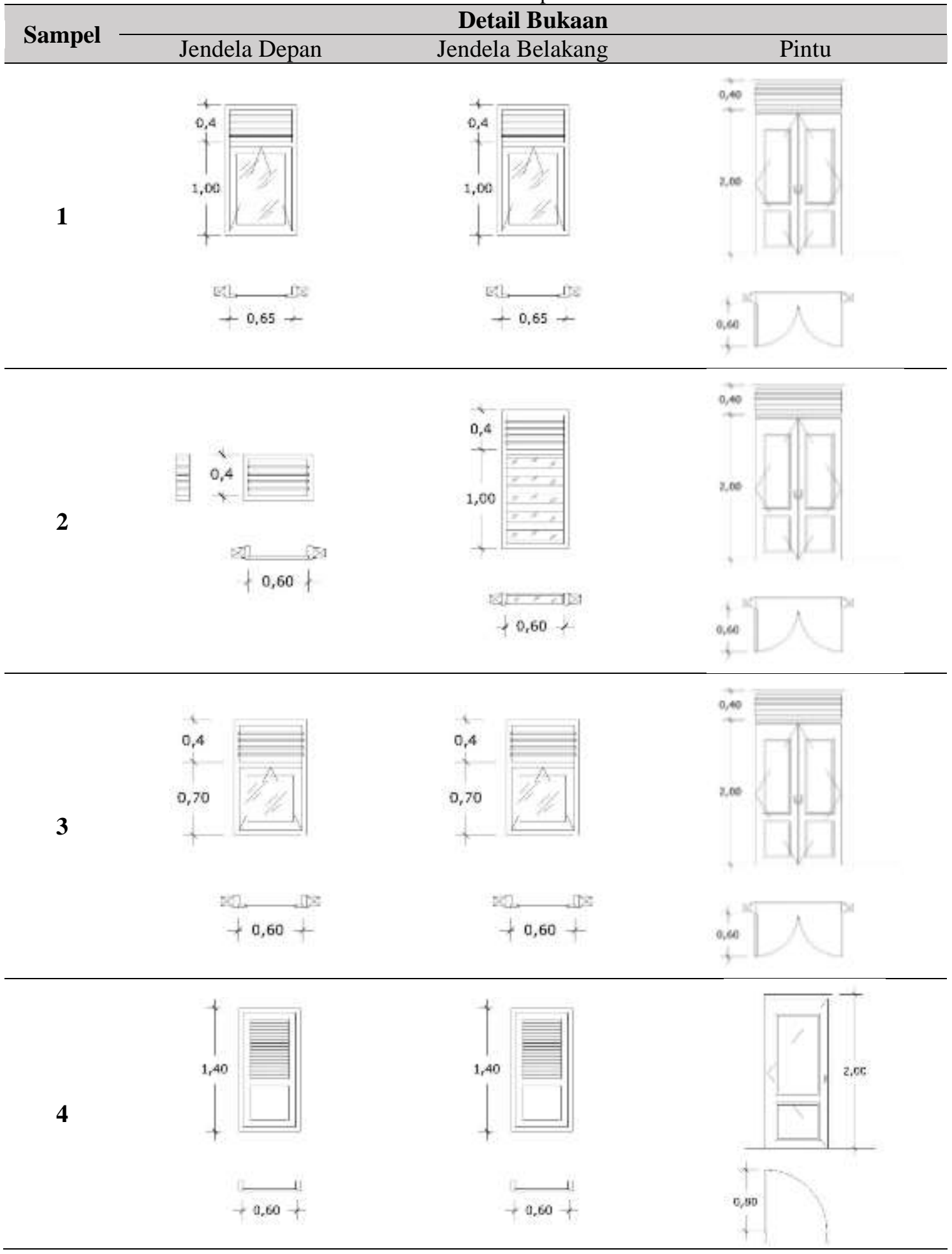


Tabel 3 Lanjutan

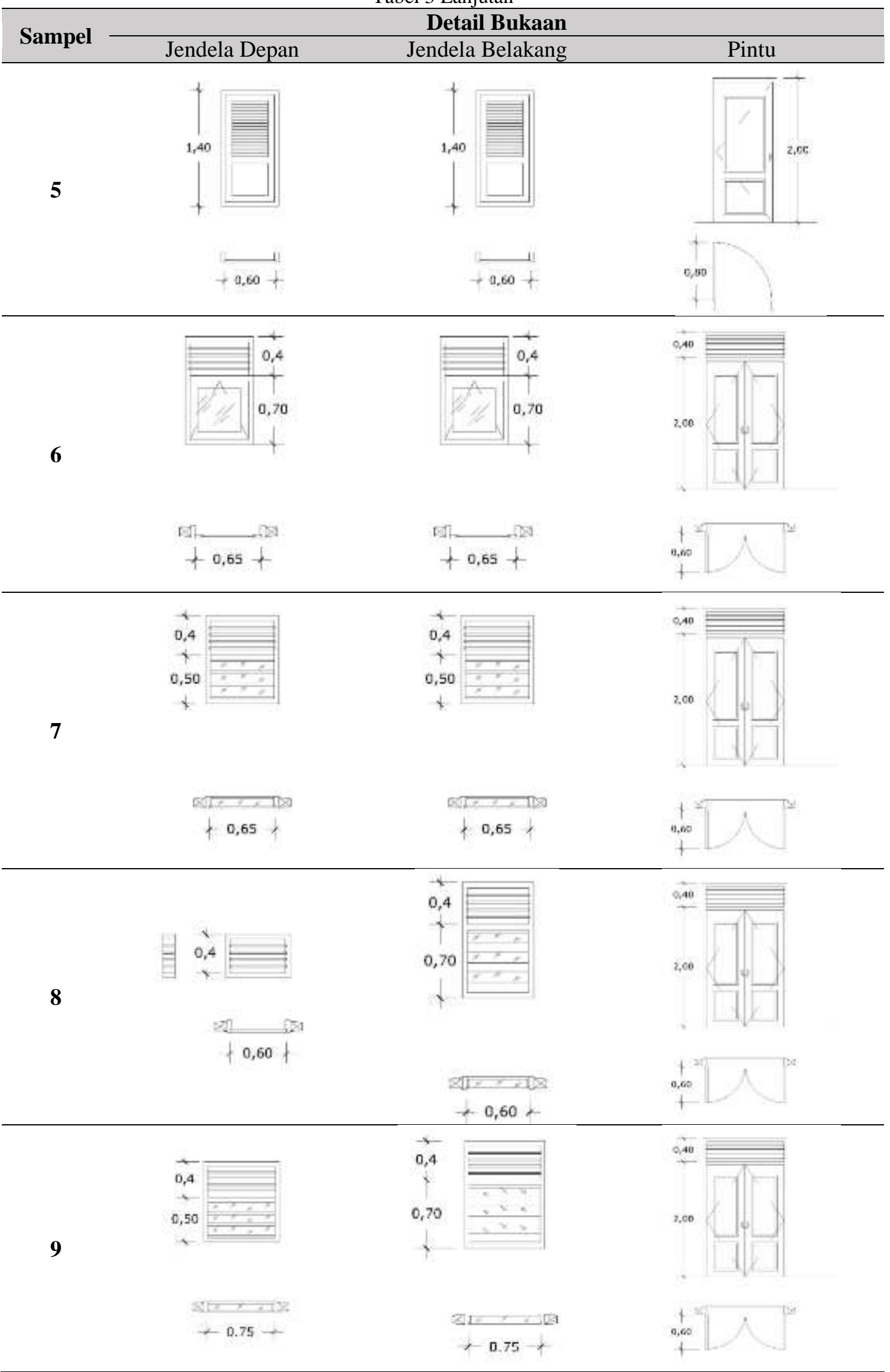


Penentuan titik ukur pencahayaan berdasarkan SNI 03-2396-2001 memiliki beberapa kesamaan terutama pada penentuan nilai kedalaman ruang (d) dan penentuan jarak antar titik sebab luasan bangunan di setiap sampel hampir memiliki kesamaan. Nilai kedalaman ruang (d) ditetapkan pada bagian tengah bangunan sebab bukaan berada pada kedua sisi dinding yang berhadapan. Nilai d yang diperoleh yaitu 3,5 $\mathrm{m}$ dan $4 \mathrm{~m}$, sedangkan ketentuan untuk setiap titik ukur baik titik ukur utama (TUU) maupun titik ukur samping (TUS) berjarak $2 \mathrm{~m}$. Setelah menentukan titik ukur pencahayaan pada tiap-tiap sampel maka metode pengukuran dengan alat lux meter dapat dilakukan. Tinggi bidang pengukuran dari permukaan lantai yaitu 0,75 $\mathrm{m}$. Pengukuran pencahayaan pada sampel dilakukan dalam dua kondisi waktu yaitu langit cerah dan langit mendung. Interval waktu pengukuran di mulai pukul 08.00-10.00 WIB, 11.00-13.00 WIB, dan 14.00-15.00 WIB. Hal lainnya harus diperhatikan adalah Nilai iluminansi di luar kelas pada saat pengukuran dapat dibedakan berdasarkan kondisi langit cerah dan mendung (tabel 4).

Tabel 4. Nilai iluminasi pada luar ruang

\begin{tabular}{ccc}
\hline Interval Waktu & $\begin{array}{c}\text { Nilai Iluminasi pada Kondisi } \\
\text { Langit Cerah (lux) }\end{array}$ & $\begin{array}{c}\text { Nilai Iluminasi pada Kondisi } \\
\text { Langit Mendung (lux) }\end{array}$ \\
\hline $08.00-10.00 \mathrm{WIB}$ & $14.146,5$ & $4.377,5$ \\
\hline $11.00-13.00 \mathrm{WIB}$ & $18.204,5$ & $6.667,2$ \\
\hline $14.00-15.00 \mathrm{WIB}$ & $20.906,4$ & $7.534,8$ \\
\hline
\end{tabular}

Penelitian dilakukan selama 2 hari, pada tanggal 10 dan 13 februari 2021. Nilai rata-rata tingkat pencahayaan yang diperoleh setiap sampel di ruang dengan kondisi langit cerah dan mendung dapat dilihat pada tabel 5. Berdasarkan tabel dibawah ini, memperlihatkan perbandingan pada sampel dengan nilai rata-rata tingkat pencahayaan alami adalah sebagai berikut:

Tabel 5. Tingkat pencahayaan alami pada ruang kelas kondisi langit cerah dan mendung

\begin{tabular}{ccccccc}
\hline \multirow{3}{*}{ Sampel } & \multicolumn{3}{c}{ Langit Cerah } & \multicolumn{3}{c}{ Langit Mendung } \\
\cline { 2 - 7 } & $08.00-10.00$ & $11.00-13.00$ & $14.00-15.00$ & $08.00-10.00$ & $11.00-13.00$ & $14.00-15.00$ \\
& WIB (lux) & WIB (lux) & WIB (lux) & WIB (lux) & WIB (lux) & WIB (lux) \\
\hline $\mathbf{1}$ & 337,05 & 408,78 & 423,156 & 43,82 & 53,14 & 55,01 \\
$\mathbf{2}$ & 248,47 & 332,77 & 346,487 & 32,30 & 43,26 & 45,04 \\
$\mathbf{3}$ & 328,95 & 383,99 & 387,00 & 42,76 & 49,92 & 50,31 \\
$\mathbf{4}$ & 79,64 & 125,13 & 141,70 & 10,35 & 16,27 & 18,42 \\
$\mathbf{5}$ & 68,88 & 111,68 & 123,28 & 8,95 & 14,52 & 16,03 \\
$\mathbf{6}$ & 237,95 & 298,27 & 319,17 & 30,93 & 38,78 & 41,49 \\
$\mathbf{7}$ & 153,91 & 254,03 & 289,21 & 20,01 & 33,02 & 37,60 \\
$\mathbf{8}$ & 191,03 & 269,85 & 296,98 & 24,83 & 35,08 & 38,61 \\
$\mathbf{9}$ & 255,05 & 346,10 & 361,23 & 33,16 & 44,99 & 46,96 \\
\hline
\end{tabular}

Berdasarkan tabel diatas, menunjukan bahwasanya nilai rata-rata pencahayaan alami dapat diketahui dengan perbandingan nilai pencahayaan pada sampel masing-masing ruang kelas. Tingkat/intensitas pencahayaan alami dari setiap sampel mulai pukul 08.00 WIB hingga 15.00 WIB dapat ditunjukkan pada gambar berikut berikut ini.

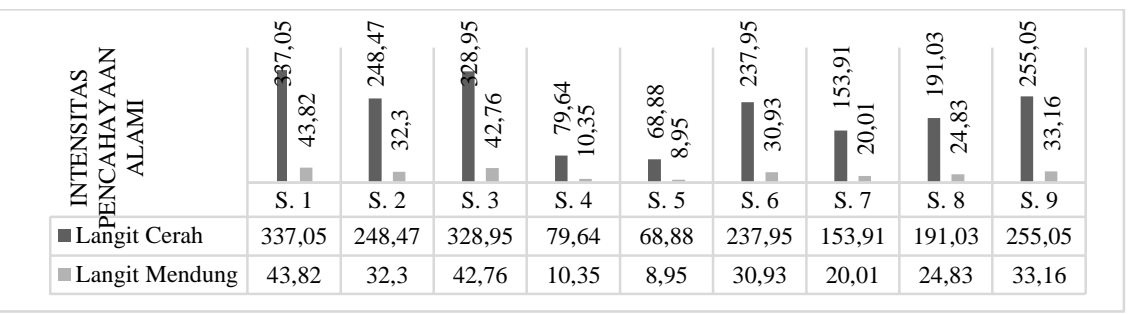

Gambar 2. Intensitas pencahayaan alami pukul 08.00-10.00 WIB

PROGRAM STUDI ARSITEKTUR UNIVERSITAS MALIKUSSALEH 


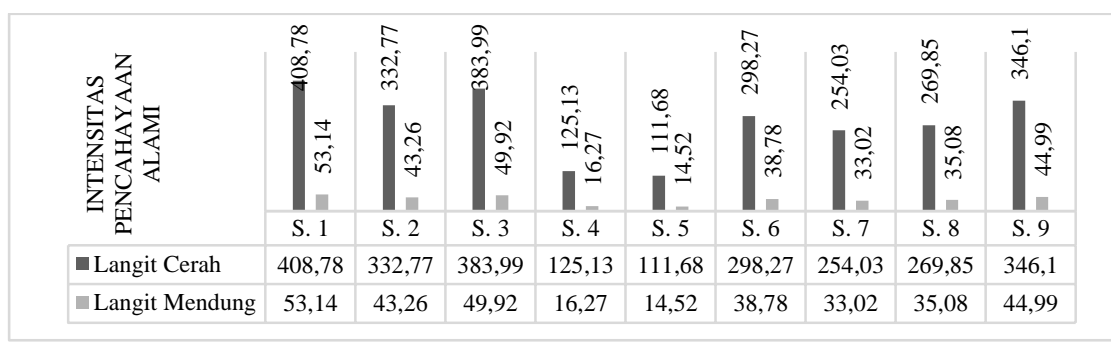

Gambar 3. Intensitas pencahayaan alami pukul 11.00-13.00WIB

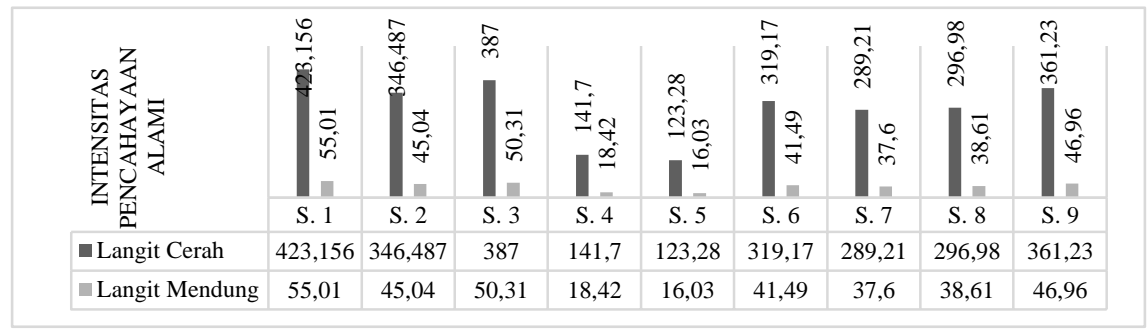

Gambar 4. Intensitas pencahayaan alami pukul 14.00-15.00 WIB

Berdasarkan gambar 2, 3 dan 4 menunjukan bahwa syarat standar pencahayaan alami ruang kelas hanya dipenuhi oleh sampel 1,3 dan 9 pada pukul 08.00-10.00 WIB, sedangkan pukul 11.00-15.00 WIB hanya sampel 4 dan 5 yang tidak memenuhi syarat standar kebutuhan pencahayaan sebuah ruang kelas. Kebutuhan pencahayaan tidak terpenuhi pada kondisi langit mendung.

Nilai iluminasi yang telah diperoleh setelah melakukan pengukuran terhadap iluminasi luar ruang dan dalam ruang akan menghasilkan nilai faktor pencahayaan alami siang hari (FPASH) dengan rumus penilaian tercantum berikut ini. Nilai faktor pencahayaan alami siang hari (FPASH) dideskripsikan sebagai berikut (tabel 6).

$$
\mathrm{FL}_{\min (\mathrm{n})}=\mathrm{E}_{1(\mathrm{n})} / \mathrm{E}_{0(\mathrm{n})} \times 100 \%
$$

$$
\begin{array}{ll}
\mathrm{FL}_{\min (\mathrm{n})} & =\text { Faktor pencahayaan siang hari (\%) } \\
\mathrm{E}_{1(\mathrm{n})} & =\text { Pengukuran di ruangan (lux) } \\
\mathrm{E}_{0(\mathrm{n})} & =\text { Pengukuran di luar ruangan (lux) }
\end{array}
$$

Tabel 6. Faktor Pencahayaan Alami Siang Hari (FPASH)

\begin{tabular}{ccccccc}
\hline \multirow{2}{*}{ Sampel } & \multicolumn{2}{c}{ FPASH Kondisi Langit Cerah (\%) } & \multicolumn{3}{c}{ FPASH Kondisi Langit Mendung (\%) } \\
\cline { 2 - 7 } & $08.00-$ & $11.00-$ & $14.00-$ & $08.00-$ & $11.00-$ & $14.00-$ \\
& $10.00 \mathrm{WIB}$ & $13.00 \mathrm{WIB}$ & $15.00 \mathrm{WIB}$ & $10.00 \mathrm{WIB}$ & $13.00 \mathrm{WIB}$ & $15.00 \mathrm{WIB}$ \\
\hline $\mathbf{1}$ & 2,38 & 2,25 & 2,02 & 1,01 & 0,80 & 0,73 \\
$\mathbf{2}$ & 1,76 & 1,83 & 1,66 & 0,74 & 0,65 & 0,60 \\
$\mathbf{3}$ & 2,33 & 2,11 & 1,85 & 0,99 & 0,75 & 0,67 \\
$\mathbf{4}$ & 0,56 & 0,69 & 0,68 & 0,24 & 0,24 & 0,24 \\
$\mathbf{5}$ & 0,38 & 0,61 & 0,59 & 0,21 & 0,22 & 0,21 \\
$\mathbf{6}$ & 1,68 & 1,64 & 1,53 & 0,71 & 0,58 & 0,55 \\
$\mathbf{7}$ & 1,09 & 1,40 & 1,38 & 0,46 & 0,50 & 0,50 \\
$\mathbf{8}$ & 1,35 & 1,48 & 1,42 & 0,57 & 0,53 & 0,51 \\
$\mathbf{9}$ & 1,80 & 1,90 & 1,73 & 0,76 & 0,67 & 0,66 \\
\hline
\end{tabular}




\section{Pembahasan Objek Penelitian}

Luas bukaan baik jendela, ventilasi maupun pintu, mampu memberikan pengaruh yang cukup signifikan terhadap kondisi pencahayaan alami yang diterima oleh ruang. Bukaan besar menghasilkan pencahayaan alami yang cukup besar jika dilihat berdasarkan hasil pengukuran. Orientasi ruang dan bukaan juga memberikan pengaruh terhadap pencahayaan seperti penggunaan bukaan pada sisi timur-barat memperoleh pencahayaan yang lebih besar dibanding orientasi utara-selatan. Hal tersebut disebabkan karena orientasi timur-barat memperoleh cahaya matahari langsung sedangkan utara-selatan mendapat pencahayaan difus.

Tipe jendela yang digunakan di setiap sampel, bertujuan untuk pencahayaan, penghawaan dan visualisasi menuju luar ruang. Ukuran bukaan juga mempengaruhi besarnya akses cahaya masuk menuju ruang. Semakin besar rasio luasan bukaan semakin besar pula akses cahaya masuk menuju ruang. Nilai rasio bukaan pada sebuah bangunan dapat diperoleh dengan rumusan berikut:

$$
W W R=\frac{\text { LuasBukaanJendela }\left(\mathrm{m}^{2}\right)}{\begin{array}{c}
\text { LuasDindingBangunan }\left(\mathrm{m}^{2}\right) \\
\text { Sumber: Setyowati, } 2015
\end{array}} \times 100 \%
$$

Berdasarkan rumusan tersebut nilai rasio bukaan pada masing-masing sampel penelitian dijelaskan pada tabel 7. Hasil penilaian WWR menunjukan persentase harus terpenuhi minimum adalah 20\%, sehingga ditemukan yang memenuhi berada pada sampel 1, 3, 6 dan 9 (tabel 7).

\begin{tabular}{|c|c|c|c|c|c|c|c|c|c|}
\hline \multirow[b]{2}{*}{ Sampel } & \multicolumn{3}{|c|}{ Ukuran Ruang } & \multirow{2}{*}{$\begin{array}{c}\text { Orientasi } \\
\text { Dpn/Blk }\end{array}$} & \multicolumn{3}{|c|}{ Luas Bukaan $\left(\mathrm{m}^{2}\right)$} & \multirow{2}{*}{$\begin{array}{c}\text { Luas } \\
\text { Dinding } \\
\left(\mathbf{m}^{2}\right)\end{array}$} & \multirow[b]{2}{*}{ WWR(\%) } \\
\hline & $\begin{array}{c}\mathrm{p} \\
(\mathrm{m})\end{array}$ & $\begin{array}{c}1 \\
(\mathrm{~m})\end{array}$ & $\begin{array}{c}\mathrm{t} \\
(\mathrm{m})\end{array}$ & & Jendela & Jalusi & Pintu & & \\
\hline \multirow{2}{*}{1} & \multirow{2}{*}{7,5} & \multirow{2}{*}{8,0} & \multirow{2}{*}{3,5} & Timur & 3,96 & 1,38 & 2,40 & 26,25 & \multirow{2}{*}{27} \\
\hline & & & & Barat & 4,95 & 1,38 & 0,00 & 26,25 & \\
\hline \multirow{2}{*}{2} & \multirow{2}{*}{9,0} & \multirow{2}{*}{8,0} & \multirow{2}{*}{3,5} & Selatan & 0,00 & 1,65 & 2,40 & 31,50 & \multirow{2}{*}{18} \\
\hline & & & & Utara & 5,40 & 1,65 & 0,00 & 31,50 & \\
\hline \multirow{2}{*}{3} & \multirow{2}{*}{9,0} & \multirow{2}{*}{8,0} & \multirow{2}{*}{3,5} & Selatan & 3,36 & 1,50 & 2,40 & 31,50 & \multirow{2}{*}{20} \\
\hline & & & & Utara & 3,78 & 1,35 & 0,00 & 31,50 & \\
\hline \multirow{2}{*}{4} & \multirow{2}{*}{7,0} & \multirow{2}{*}{7,0} & \multirow{2}{*}{3,5} & Selatan & 2,60 & 0,00 & 1,56 & 24,50 & \multirow{2}{*}{14} \\
\hline & & & & Utara & 2,60 & 0,00 & 0,00 & 24,50 & \\
\hline \multirow{2}{*}{5} & \multirow{2}{*}{9,0} & \multirow{2}{*}{7,0} & \multirow{2}{*}{3,5} & Selatan & 2,60 & 0,00 & 1,56 & 31,50 & \multirow{2}{*}{13} \\
\hline & & & & Utara & 3,90 & 0,00 & 0,00 & 31,50 & \\
\hline \multirow{2}{*}{6} & \multirow{2}{*}{9,0} & \multirow{2}{*}{7,0} & & Barat & 2,64 & 2,64 & 1,38 & 2,40 & 20 \\
\hline & & & 3,0 & Timur & 3,00 & 3,00 & 1,25 & 0,00 & \\
\hline 7 & & 70 & 35 & Utara & 1,76 & 1,76 & 1,38 & 2,40 & 15 \\
\hline 1 & 8,0 & 1,0 & 3,5 & Selatan & 1,76 & 1,76 & 1,10 & 0,00 & \\
\hline 8 & 90 & 70 & 35 & Utara & 0,00 & 0,00 & 1,50 & 2,40 & 14 \\
\hline 8 & 9,0 & 1,0 & 3,5 & Selatan & 3,60 & 3,60 & 1,50 & 0,00 & \\
\hline 0 & 80 & 70 & 30 & Utara & 2,08 & 2,08 & 1,63 & 2,40 & 22 \\
\hline 9 & $\delta, 0$ & 1,0 & 5,0 & Selatan & 3,12 & 1,30 & 0,00 & 24,00 & \\
\hline
\end{tabular}

Tabel 7. Rasio Bukaan pada Sampel Penelitian

Hubungan rasio bukaan (WWR) terhadap iluminasi cahaya alami berdasarkan keseluruhan ruang yang telah diamati akan dideskripsikan melalui gambar sebagai berikut. 


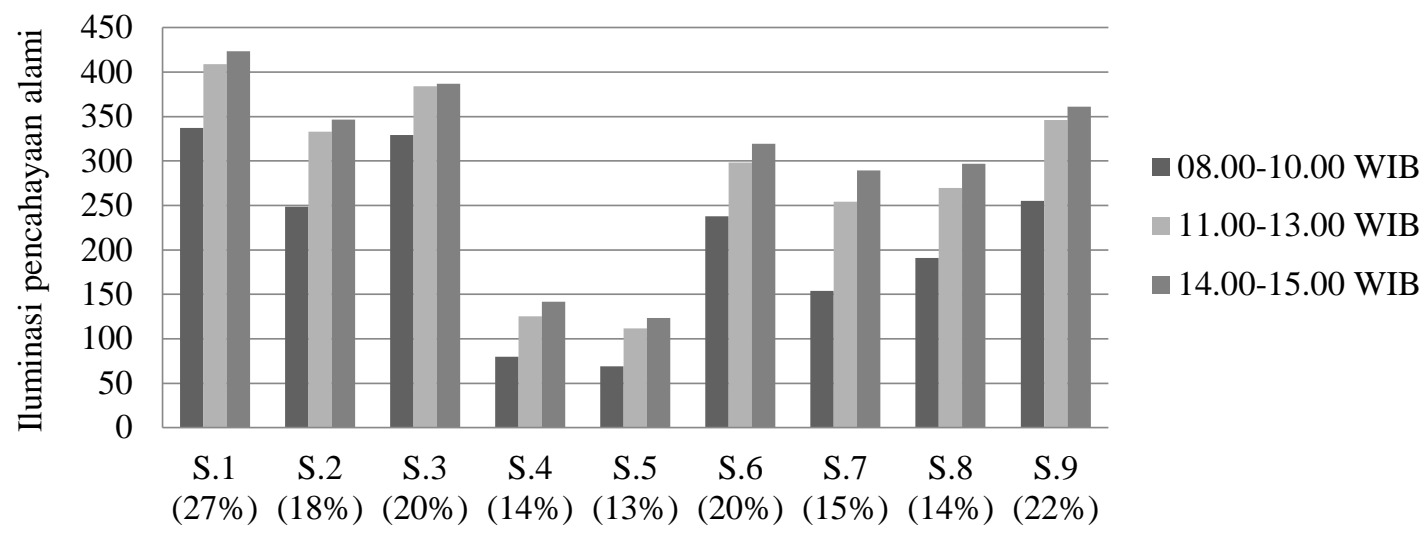

Gambar 5. Perbandingan WWR dan Iluminasi Cahaya Kondisi Langit Cerah

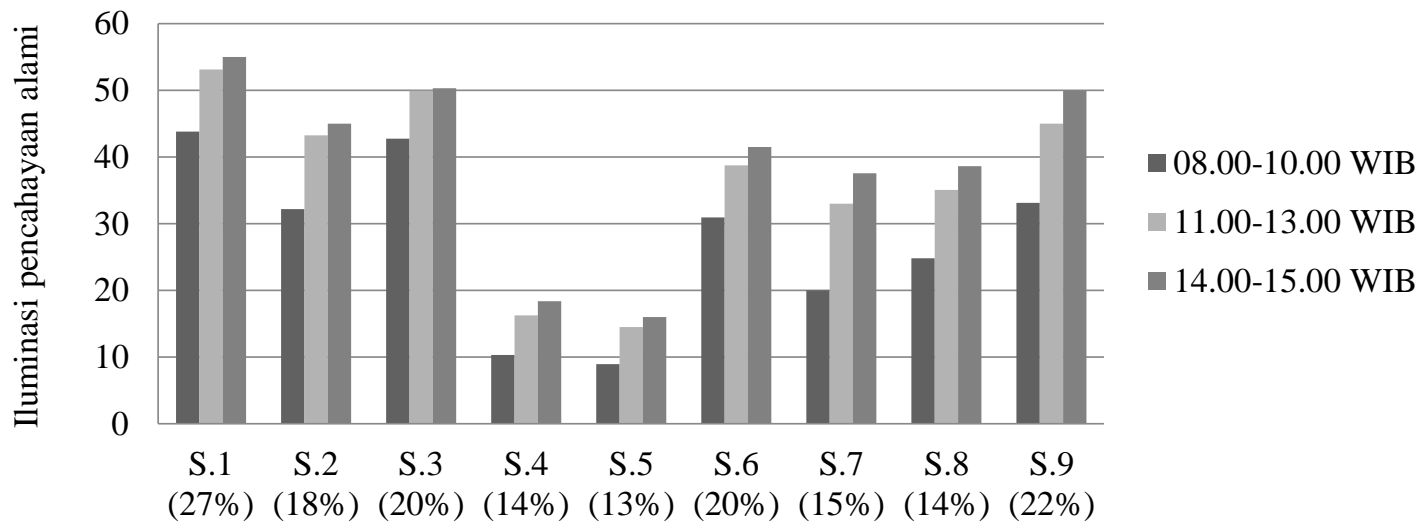

Gambar 6. Perbandingan WWR dan Iluminasi Cahaya Kondisi Langit Mendung

Berdasarkan nilai wwr pada grafik di atas, menjelaskan bahwasanya rasio bukaan akan memberikan pengaruh yang cukup signifikan terhadap kondisi pencahayaan alami yang diterima ruang. Bukaan pada sampel penelitian ini sebaiknya di desain dengan pertimbangan rasio bukaan dan memperhatikan faktor-faktor penghalang cahaya di sekitar bangunan agar cahaya dapat masuk menuju ruang secara optimal. Bukaan juga di desain dengan memperhatikan rasio bukaan minimum $20 \%$ berdasarkan hasil penelitian yang diperoleh. Berbeda halnya dengan sampel 6 yang memiliki nilai wwr sebesar 20\% namun cahaya yang diterima belum mencukupi. Berdasarkan pengamatan, menunjukan pada sisi depan (barat) terdapat vegetasi yang tepat menghalangi bukaan jendela sehingga pencahayaan alami tidak terpenuhi.

Hal ini menunjukan bahwasanya, standar pencahayaan alami terpenuhi ketika ruang memiliki wwr minimal sebesar $20 \%$ tanpa adanya faktor penghalang disekitar bangunan. Hasil penelitian menemukan ruang yang memenuhi standar pencahayaan alami yaitu sampel 1,3 dan 9, sedangkan ruang pada sampel 2,4,5,7 dan 8 WWR tidak terpenuhi nilai minimum. Berbeda dengan sampel 6 nilai wwr terpenuhi akan tetapi adanya faktor penghalang sehingga intensitas pencahayaan tidak memenuhi standar.

Berdasarkan tingkat pencahayaan alami ditemukan pada pukul 08.00-10.00 yang memenuhi standar hanya pada sampel 1,3 dan 9; pada pukul 11.00-13.00 dan pukul 14.00-15.00 semua memenuhi kecuali pada sampel 4 dan 5 (tabel 8). Berbeda halnya ketika langit mendung maka pencahayaan alami tidak memenuhi standart pada semua sampel (tabel 9). 
Tabel 8. Tingkat pencahayaan alami yang terpenuhi pada kondisi langit cerah

\begin{tabular}{|c|c|c|c|c|c|c|}
\hline \multirow{2}{*}{ Sampel } & \multicolumn{6}{|c|}{ Langit Cerah } \\
\hline & $\begin{array}{c}08.00-10.00 \\
\text { WIB (lux) }\end{array}$ & Keterangan & $\begin{array}{c}11.00-13.00 \\
\text { WIB (lux) }\end{array}$ & Keterangan & $\begin{array}{c}14.00-15.00 \\
\text { WIB (lux) }\end{array}$ & Keterangan \\
\hline 1 & 337,05 & MS & 408,78 & MS & 423,156 & MS \\
\hline 2 & 248,47 & TMS & 332,77 & MS & 346,487 & MS \\
\hline 3 & 328,95 & MS & 383,99 & MS & 387,00 & MS \\
\hline 4 & 79,64 & TMS & 125,13 & TMS & 141,70 & TMS \\
\hline 5 & 68,88 & TMS & 111,68 & TMS & 123,28 & TMS \\
\hline 6 & 237,95 & TMS & 298,27 & MS & 319,17 & MS \\
\hline 7 & 153,91 & TMS & 254,03 & MS & 289,21 & MS \\
\hline 8 & 191,03 & TMS & 269,85 & MS & 296,98 & MS \\
\hline 9 & 255,05 & MS & 346,10 & MS & 361,23 & MS \\
\hline
\end{tabular}

Tabel 9. Tingkat pencahayaan alami yang terpenuhi pada kondisi langit mendung

\begin{tabular}{ccccccc}
\hline \multirow{2}{*}{ Sampel } & \multicolumn{6}{c}{ Langit Cerah } \\
\cline { 2 - 7 } & $\begin{array}{c}08.00-10.00 \\
\text { WIB (lux) }\end{array}$ & \multirow{2}{*}{ Keterangan } & $\begin{array}{c}11.00-13.00 \\
\text { WIB (lux) }\end{array}$ & Keterangan & $\begin{array}{c}14.00-15.00 \\
\text { WIB (lux) }\end{array}$ & Keterangan \\
\hline $\mathbf{1}$ & 43,82 & TMS & 53,14 & TMS & 55,01 & TMS \\
$\mathbf{2}$ & 32,30 & TMS & 43,26 & TMS & 45,04 & TMS \\
$\mathbf{3}$ & 42,76 & TMS & 49,92 & TMS & 50,31 & TMS \\
$\mathbf{4}$ & 10,35 & TMS & 16,27 & TMS & 18,42 & TMS \\
$\mathbf{5}$ & 8,95 & TMS & 14,52 & TMS & 16,03 & TMS \\
$\mathbf{6}$ & 30,93 & TMS & 38,78 & TMS & 41,49 & TMS \\
$\mathbf{7}$ & 20,01 & TMS & 33,02 & TMS & 37,60 & TMS \\
$\mathbf{8}$ & 24,83 & TMS & 35,08 & TMS & 38,61 & TMS \\
$\mathbf{9}$ & 33,16 & TMS & 44,99 & TMS & 46,96 & TMS \\
\hline
\end{tabular}

Keterangan:

MS : Memenuhi Syarat

TMS : Tidak Memenuhi Syarat

Adapun sampel-sampel yang tidak memenuhi syarat standar pencahayaan alami antara lain sampel 2, 4, 5, 6, 7 dan 8 diuraikan sebagai berikut:

a. Sampel 2

Sampel 2 hanya menggunakan ventilasi sehingga cahaya yang masuk menuju ruang sangat minim. Bukaan berupa ventilasi pada sampel 2 dapat dilihat pada gambar berikut:

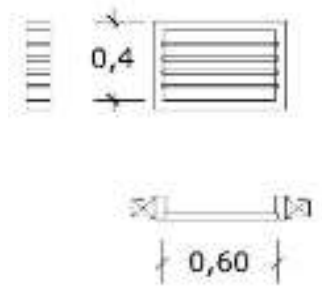

Gambar 7. Bukaan pada sampel 2

Bukaan sampel 2 berada pada posisi yang sama dengan sampel 3, maka saran bukaan disesuaikan dengan bukaan sampel 3 karena memenuhi kebutuhan syarat standar pencahayaan alami. Bukaan pada sampel 2 pada sisi selatan dapat diganti dengan desain bukaan sebagai berikut: 


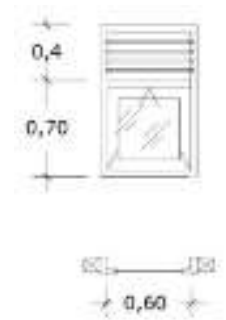

Gambar 8. Saran bukaan sampel 2

Saran bukaan pada sampel 2 dapat mengikuti desain bukaan pada sampel 3, dengan tipe bukaan dan jumlah bukaan yang sama karena memiliki luas ruang yang sama.

\section{b. Sampel 4 dan 5}

Ditinjau berdasarkan bukaan dengan posisi yang tidak merata sehinga sebaran cahaya yang dihasilkan juga tidak merata. Posisi bukaan pada sampel 4 dan 5 dapat dilihat pada gambar berikut:

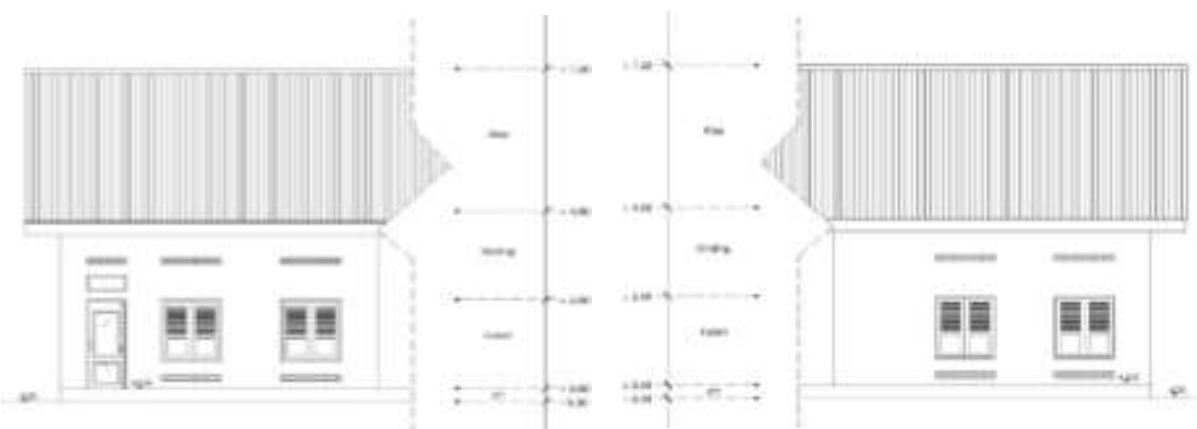

Gambar 3.3 Sebaran bukaan sampel 4
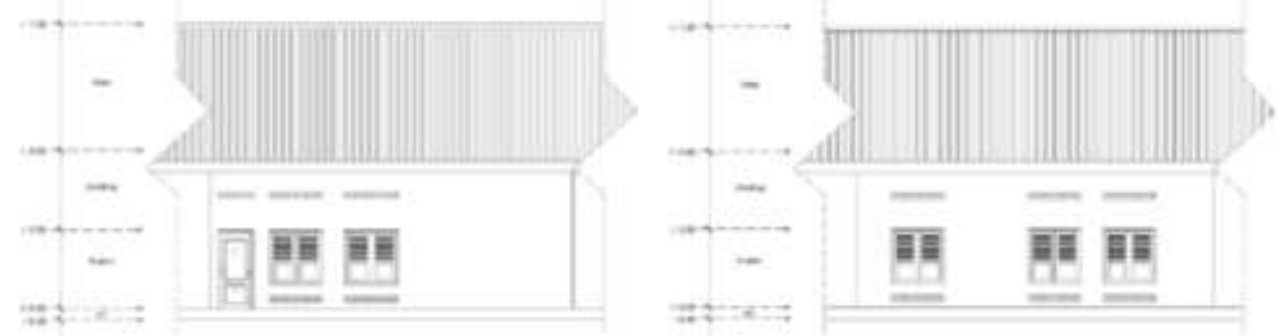

Gambar 9. Sebaran bukaan sampel 5

Sampel 4 dan 5 memiliki nilai WWR terkecil yaitu $14 \%$ dan $15 \%$, maka sampel ini memiliki nilai WWR yang belum memadai sehingga membutuhkan penambahan jumlah bukaan pada ruang dengan posisi sebaran yang merata sehingga dapat memenuhi standar pencahayaan alami.

\section{c. Sampel 6}

Berdasarkan wwr memenuhi, akan tetapi terhalang pencahayaan alaminya sehingga tidak mencukupi kebutuhan pencahayaan pada ruang. Berdasarkan orientasi ruang mengarah timur dan barat yang memperoleh cahaya matahari secara langsung. Kendalanya pencahayaan tidak memenuhi, terlihat vegetasi pada sisi bagian depan bangunan.

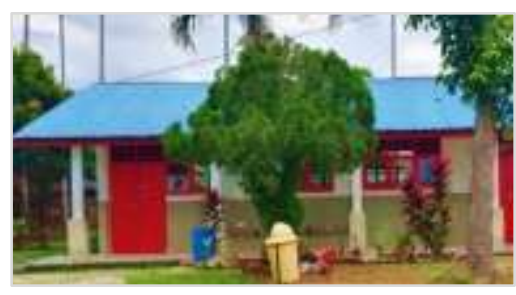


Perlu diperhatikan pemilihan vegetasi yang tepat disekeliling bangunan untuk menghindari terhalangnya cahaya menuju bangunan.

\section{d. Sampel 7}

Sampel 7 menggunakan bukaan dengan tipe jendela nako dengan nilai WWR dibawah $20 \%$. Permasalahan pada sampel 7 dapat ditinjau kembali berdasarkan gambar dibawah ini, memperlihatkan posisi sampel yang terhimpit dengan bangunan baik di sisi selatan ruang, sedangkan pada posisi utara terdapat vegetasi sehingga memungkinkan terjadinya pembayangan.

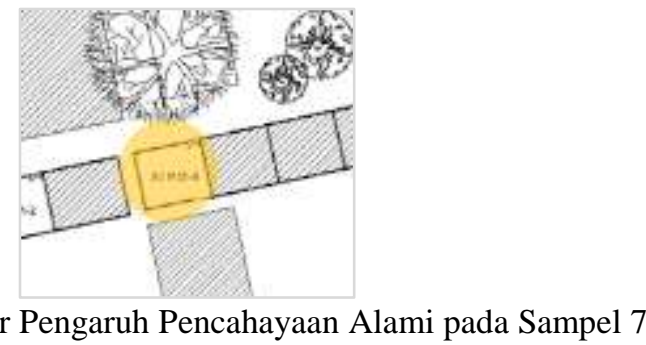

Faktor yang mempengaruhi pencahayaan alami pada sampel ini yaitu bangunan di sisi selatan dan vegetasi di sisi utara. Hal tersebut memberi pengaruh secara langsung sebab bukaan pada sampel ini berorietasi ke selatan dan utara. Vegetasi disekitar bangunan sebaiknya menggunakan vegetasi yang tidak terlalu besar untuk menghindari terjadinya penghambatan cahaya menuju ruang.

\section{e. Sampel 8}

Sampel 8 memiliki permasalahan yang sama dengan sampel 2. Sampel 8 juga menggunakan ventilasi pada sisi utara ruang. Hal tersebut menyebabkan cahaya yang masuk menuju ruang sangat sedikit. Sampel 8 berada pada posisi yang sama dengan sampel 9. Sampel 8 juga memiliki ukuran ruang yang sama dengan sampel 9 sehingga bukaan pada sampel 9 dapat diterapkan pada sampel 8 di sisi utara ruang.

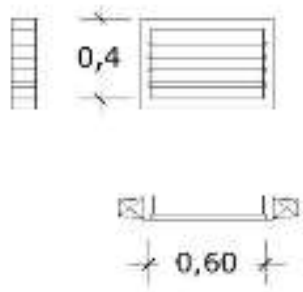

Gambar 3.7 Saran bukaan sampel 8

\section{KESIMPULAN DAN SARAN}

Kondisi pencahayaan alami pada ruang kelas di SMA Negeri 1 Dolok Batu Nanggar belum seluruhnya memenuhi syarat standar kebutuhan cahaya alami ruang kelas berdasarkan SNI. Kebutuhan pencahayaan alami terpenuhi pada sampel 1, 3 dan 9 pada pukul 08.00-15.00 WIB. Sampel 2, 7, 6 dan 8 memenuhi kebutuhan pencahayaan pada pukul 11.00-15.00 WIB, sedangkan sampel 4 dan 5 tidak memenuhi standar mulai pukul 08.00 hingga 15.00 WIB. Rasio dan orientasi bukaan memberikan pengaruh yang cukup besar terhadap pencahayaan alami pada penelitian ini. Tingkat dan sebaran pencahayaan alami tidak hanya dipengaruhi oleh desain 
bukaan, melainkan juga faktor-faktor lain disekitar bangunan seperti bangunan lain ataupun vegetasi disekitarnya.

Saran bukaan pada penelitian ini sebaiknya didesain dengan mempertimbangkan rasio bukaan dan faktor-faktor penghalang cahaya di sekitar bangunan agar cahaya dapat masuk menuju ruang secara optimal. Bukaan sebaiknya didesain dengan rasio bukaan minimum 20\% berdasarkan hasil penelitian yang diperoleh pada keseluruhan sampel.

\section{DAFTAR PUSTAKA}

[1] P. Manurung, Pencahayaan Alami dalam Arsitektur. Yogyakarta, 2012.

[2] N. Lechner, Heating, Cooling, Lighting, 2nd ed. Jakarta: PT RajaGrafindo persada, 2007.

[3] M. Seidl, "Daylight in Living-Rooms.," no. June, pp. 273-276, 1980.

[4] D. Phillips and C. Gardner, Daylighting: Natural light in architecture. 2012.

[5] A. . Tamrin, Teknik Konstruksi Bangunan Gedung, 2nd ed. Jakarta: Direktorat Pembinaan Sekolah Menengah Kejuruan, 2008.

[6] N. L. Latifah, Fisika Bangunan, 2nd ed. Jakarta, 2015.

[7] SNI, "Tata cara perancangan sistem pencahayaan alami pada bangunan gedung." Badan Standarisasi Nasional, 2001.

[8] S. Juddah, R. Rahim, and R. Wikantari, "pengaruh orientasi dan luas bukaan terhadap intensitas pencahayaan pada ruang laboratorium,” Konsentrasi Tek. Arsit., 2013.

[9] C. Vidiyanti, R. Siswanto, and F. Ramadhan, "Pengaruh bukaan terhadap pencahayaan alami dan penghawaan alami pada Masjid Al Ahdhar Bekasi," J. Arsit. Zo., vol. 3, no. 1, pp. 20-33, 2020, doi: 10.17509/jaz.v3i1.18621.

[10] R. Bean, Lighting Interior and Exterior, 1st ed. USA, 2004.

[11] R. D. Chaerani, Suprayogi, and E. Djunaedy, "Optimalisasi bukaan jendela untuk pencahayaan alami dan konsumsi energi bangunan,” e-Proceeding Eng., vol. 4, no. 3, pp. 3936-3944, 2017. 